\title{
UTILIZAÇÃO DE PRÁTICAS ALTERNATIVAS DA FILOSOFIA DE VIDA SEICHO-NO-IE VOLTADAS PARA AÇÕES DE EDUCAÇÃO AMBIENTAL
}

\author{
Estefania Bertoldo Venturini ${ }^{1}$, Vânia Medianeira Flores Costa ${ }^{2}$ \\ ${ }^{1}$ Especialista em Educação Ambiental - UFSM \\ tefaventurini@hotmail.com \\ ${ }^{2}$ Profa. Orientadora - Curso de Especialização em Educação Ambiental - UFSM \\ vania.costa@ufsm.br
}

\section{Resumo}

A crise ambiental estabelecida requer uma educação transformadora e com esse ideal têm-se as propostas da Educação Ambiental. Diante dessa questão, este artigo resgata aspectos filosóficos da Educação Física que relacionados as necessidades educacionais atuais supõe-se contribuir para o desenvolvimento e aprimoramento das percepções. Como ferramenta propõe-se algumas práticas alternativas trazidas pelos ensinamentos educacionais da Seicho-No-le, uma filosofia de vida prática com aspecto religioso. A carência de trabalhos reflexivos que abordem o homem como um ser uno, na disciplina de Educação Física, justifica a elaboração desse documento que teve como objetivo principal construir bases metodológicas para auxiliar os profissionais dessa área a contribuírem significativamente com as ações de Educação Ambiental. Como objetivo secundário, através de uma perspectiva mais holística de percepção pretendeu-se inovar as relações entre a Educação Física e as áreas naturais do conhecimento, enfatizando os aspectos educacionais dessa disciplina. Através da filosofia de vida Seicho-No-le surgem novas perspectivas de trabalho e visando a transformação da percepção individual para o aprimoramento da percepção holística de mundo, propõem-se algumas práticas, correlacionando-as com as ações de Educação Ambiental.

Palavras chave: Educação Física. Educação Ambiental. Filosofia de Vida. Práticas Alternativas.

\begin{abstract}
The established environment crisis requires a transforming education and with this ideal we have the proposals of the Ambient Education. Ahead of this question, this article rescues philosophical aspects of the Physical Education that related with the current educational necessities assumed to contribute for the development and improvement of the perceptions. As tool we considers some alternative practices that are brought for the educational teachings of the Seicho-No-le, One philosophy of practical life with religious aspect. The lack of reflective works that approach the man as a unique being into the discipline of Physical Education, justifies the elaboration of this document that had as main objective to construct methodological bases to assist the professionals of this area to contribute significantly with the actions of Environmental Education. As secondary objective through a more holistic perspective of perception it was intended to innovate the relations between the Physical Education and the natural areas of the knowledge, emphasizing the educational aspects of this discipline. Through the philosophy of life Seicho-No-le, appears new perspectives of work and aiming at the transformation of the individual perception for the improvement of the holistic perception of the world, some practical for action of Ambient Education are proposed.
\end{abstract}


Key-words: Physical Education. Environmental Education. Philosophy of Life. Practical Alternatives.

\section{Introdução}

Diante da significativa modificação de valores a Educação Ambiental poderá encontrar suas raízes nos ensinamentos filosóficos que engrandecem o espírito humano. De acordo com a Lei no. 9.795/95 (PLANALTO, 2011), a Educação Ambiental constitui-se de processos pelos quais indivíduos e coletividade constroem mediações visando a reconstrução de valores sociais, conhecimentos, habilidades, atitudes e competências voltadas para conservação e preservação do meio ambiente, essencial à sadia qualidade de vida e a sustentabilidade. Devido às particularidades do desenvolvimento humano, não existe um modelo de homem e comportamento que se possa afirmar como o certo (PAPALIA E OLD, 2000), porém Grun (2002) aponta que o modelo cartesiano, fragmentado, reducionista, mecânico e sem vida pode ser reformulado a partir de uma matriz mais complexa, orgânica e holística e através de pensamentos que unificam os seres, pode-se encontrar a oportunidade de redefinir valores e criar modelos conceituais racionais para construção de uma nova cultura. Nesse aspecto, Sorrentino (apud MARINHO, 2007) apresenta alguns atributos para a Educação Ambiental, entre eles, propiciar um autoconhecimento que contribua para o desenvolvimento de valores, atitudes, comportamentos e habilidades.

Partindo de linhas pedagógicas filosóficas, a Educação Física na sua imensidão da liberdade, imaginação e criatividade, poderá encontrar possibilidades para uma educação humanizadora que transcenda os princípios da competição, do rendimento e do confronto, (SANTIN, 2003). As propostas dessa área do conhecimento para auxiliar nas questões de Educação Ambiental têm apresentado resultados positivos nas relações entre homens e natureza, principalmente nas questões de bem estar físico e mental, (MONTEIRO, 2004; TAHARA, FILHO E SCHWARTZ, 2006; LEITE E HARTMAN, 2007; MARINHO E INÁCIO, 2007; TAHARA E FILHO, 2009), porém ainda encontram-se presas nos aspectos esportivos, apresentando-se como Atividades Físicas de Aventura na Natureza (AFANs).

Aumentar o poder das iniciativas baseadas na premissa de um maior acesso à informação e transparência na administração dos problemas ambientais urbanos pode implicar na reorganização do poder e da autoridade (JACOBI, 2003). Conforme Leite e Hartmann (2007) é diretamente no homem que a Educação Física encontra sua razão de ser, e o seu fundamento básico é a antropologia. A proposta para uma antropologia universal, segundo os autores, nasceu dos esquemas de racionalidade, que considera o homem como um ser uno, que se movimenta, brinca e sente, sugerindo a possibilidade de direcionar a aprendizagem para a compreensão ampla de idéias e valores indispensáveis na sociedade. Com o passar do tempo o homem foi desenvolvendo um conjunto de manifestações fisiológicas, comportamentais, cognitivas e emocionais para adaptar-se durante o processo de evolução (BRANDOLT, 2006). Atualmente as práticas corporais alternativas estão cada vez mais presentes no cotidiano e segundo Araujo e Araujo (2000), desempenham um papel fundamental na manutenção da saúde física e mental, bem como na promoção da qualidade de vida, sendo reconhecidas e recomendadas pelos médicos.

A legitimidade da Educação Física poderá encontrar suas bases nos aspectos fundamentais do fluir da existência. Percebendo-se que o próprio pensamento se constitui de 
movimentos, reduzir o movimento do homem aos exercícios físicos empobrece a cultura e para mudar essas concepções, não basta reformular os currículos, mas compreender o movimento humano no contexto de todas as suas dimensões (SANTIN, 2003). Considerando-se que a participação espontânea nas atividades proporcionadas é um meio de levar os indivíduos a evoluírem naturalmente para uma visão holística de mundo e assim assumirem a sua responsabilidade social, o conceito de holísmo ganha enfoque nos trabalhos de Educação Ambiental (SATO E CARVALHO, 2005). De acordo com as autoras este conceito traz como proposta a reflexão filosófica, que tem como função desenvolver uma percepção compreensiva e interpretativa da realidade, buscando o esclarecimento das verdades ocultas para recuperar o sentido original dessas verdades.

Tendo como principal objetivo, construir bases metodológicas para auxiliar os profissionais de Educação Física a contribuírem significativamente com as questões de Educação Ambiental, com base em estudos filosóficos da cultura humana, apresenta-se aos educadores essa proposta de trabalho. Nos festivais Pan-Helênicos na Grécia, onde as áreas da Educação Física encontram sua originalidade, os jogos olímpicos eram importantes pela autoridade dos juízes, pela participação festiva e livre de todos os cidadãos e pela honra de ser vencedor (SANTIN, 2003). O pan-helenismo, segundo dados históricos, significava um momento de união, fraternidade e aprimoramento da consciência helênica, tendo como propósito a língua e a recordação do antepassado comum. Os festivais tinham aspectos religiosos, mas compreendiam também expressões corporais através de concursos e provas atléticas, poéticas, musicais, representações dramáticas, canto e dança. A cultura permeava o bem-estar físico e mental, comum a todos os gregos (PAN-HELÉNICOS, 2011). Resgatando-se esses aspectos, como objetivo secundário pretendeu-se inovar as relações entre a Educação Física e a Educação Ambiental e ampliar a atuação profissional na incessante busca pela transformação do pensamento moderno.

Assim, partindo-se de investigações em livros, revistas e sites, bem como participação em cursos e eventos, encontraram-se algumas práticas pedagógicas trazidas pelos ensinamentos da Seicho-No-le, as quais estão descritas ao final desta pesquisa. A Seicho-No-le é uma filosofia de vida prática com aspecto religioso e seus ensinamentos abrangem todos os aspectos da vida humana, sendo que no setor educacional visa contribuir para a formação de uma cultura de paz e respeito as múltiplas manifestações da Vida de Deus na Terra (SNI, 2011).

\section{Metodologia}

Este artigo se construiu a partir do levantamento e seleção de informações contidas em livros, revistas e sites eletrônicos, com propósito de inovar as relações entre a Educação Ambiental e a Educação Física e em uma perspectiva mais holística de percepção, contextualizou-se com maior abrangência os aspectos das ciências humanas que visam encontrar soluções para os problemas educacionais atuais. Proveniente dessas características, Gil (2002) classifica o presente documento como uma pesquisa bibliográfica.

Conforme Amaral (2007), a pesquisa bibliográfica é uma etapa fundamental para o desenvolvimento de trabalhos científicos. Com o objetivo principal de construir bases metodológicas para auxiliar os profissionais de Educação Física a contribuírem significativamente com as questões de Educação Ambiental a partir de uma perspectiva mais holística de percepção, destacam-se as contribuições filosóficas e educacionais dessa área do conhecimento. Partindo da hermenêutica da compreensão para a percepção holística dos educadores, proporcionando o autoconhecimento sugerido pela Educação Ambiental, foram correlacionadas e descritas as 
práticas propostas pela Superintendência dos Educadores da Seicho-No-le, uma filosofia de vida ainda pouco conhecida, mas com preleções aceitas e praticadas globalmente, pois seus ensinamentos abrangem todos os aspectos essenciais da vida humana.

\section{Resultados e discussão}

Atualmente vive-se em crise de desequilíbrio ambiental e essa abrange uma série de questões essencialmente relacionadas com as representações da vida social. Segundo Garcia e Lemos (2003) manifesta-se a era da plasticidade onde as representações visuais do ser determinam o seu valor humano. A Ecologia segundo Morin (2002), que tem um ecossistema como objeto de estudo, recorre a múltiplas disciplinas e às ciências humanas contribuem para analisar as interações entre o mundo humano e a biosfera, associando as questões distintas, pois segundo ele, conhecer o humano é situá-lo no Universo.

A Seicho-No-le é uma filosofia de vida com aspecto religioso, que tem como objetivo despertar no coração das pessoas os sentimentos de filhos de Deus e fazer com que, através de atos, palavras e pensamentos, este mundo torne-se cada vez melhor. Segundo as informações contidas no site da Seicho-No-le do Brasil (SNI, 2011), essa filosofia foi fundada em 10 de março de 1930, no Japão, por Massaharu Taniguchi. Entre os líderes espirituais do Japão esse Mestre é um dos mais conhecidos e influentes, pois através de suas preleções, livros, artigos, revistas, entre outros, atinge milhões de pessoas. Suas mensagens são simples e objetivas, sendo essas capazes de modificar vidas.

Constata-se ainda que a filosofia é um ensinamento de amor que prega que o ser humano é filho de Deus e que o mundo da matéria é projeção da mente, revelando-nos a verdadeira natureza humana. É uma filosofia que transcende o sectarismo religioso acreditando que todas as religiões são luzes de salvação que emanam de um único Deus, por esse motivo ha pessoas que, mesmo sendo adeptas de uma religião, sentem-se muito bem e felizes ao entrar em contato com os ensinamentos da Seicho-No-le, que por sua vez recebe a todos, com muito amor e carinho, sem nenhuma restrição (SNI do BRASIL, 2011). Aqueles que praticam os ensinamentos da Seicho-No-le, segundo as informações explanadas pelo site, aprendem a reconhecer em sua natureza o verdadeiro filho de Deus e, em conseqüência disso, começam a vivenciar fatos que transformam a vida, como por exemplo, a cura de doenças, a reconciliação de lares em desarmonia, a exteriorização de grandes talentos, o êxito na profissão, a solução de problemas econômicos e amorosos, entre outros. Esses fatos são comprovados através de relatos expressos pelos praticantes nas reuniões doutrinárias das Associações Locais (AL), Academias de Treinamento Espiritual, e publicações em livros. Esses relatos também podem ser facilmente encontrados nas edições da Revista Sagrada "Seicho-No-le Pomba Branca", publicadas mensalmente.

Os ensinamentos da Seicho-No-le se estendem aos diversos aspectos da cultura humana, por essa razão, os estudos dessa filosofia estão divididos em cinco associações com atividades específicas, as quais se denominam: Associação Fraternidade, Associação Pomba Branca, Associação dos Jovens, Associação da Prosperidade e Superintendência das Atividades dos Educadores (SNI do BRASIL, 2011). Com base nos ensinamentos do Mestre Massaharu Taniguchi todas as associações da Seicho-No-le vem difundindo o modus vivendi, no qual se reverenciam todas as coisas do Universo através do sentimento de gratidão. Acredita-se que a aplicação prática desse sentimento na vida diária é a chave para solucionar todos os problemas, portanto a SeichoNo-le, segundo as informações obtidas no site, compromete-se a contribuir para a 
sustentabilidade do planeta e mantendo o equilíbrio entre a rentabilidade e a redução dos impactos ambientais é a única entidade religiosa do Brasil a possuir a certificação ISO 14001. Para Sampaio (2004): "é necessário repensar a educação para que esta venha servir a vida, á realização humana, social e ambiental" (p. 37).

Como possibilidades para construção dos ideais de paz, liberdade e justiça social, além das disciplinas que ensinam conhecer o meio ambiente natural para aprender a preservá-lo, destacam-se as disciplinas voltadas para o autoconhecimento no sentido de manter a saúde física e mental (RÊGO E ROCHA, 2009). Nos ensinamentos dessa filosofia percebe-se a possibilidade de desenvolver atividades educacionais, tanto para o aprimoramento pessoal quanto profissional, pois conforme uma avaliação realizada através de oficinas, pelas autoras Rêgo e Rocha (2009), onde foi submetido quatorze pedagogas, constatou-se que a inteligência emocional é essencial para que o intelecto de o melhor de si. Conforme aumenta a inteligência emocional aumenta também a capacidade intelectual, demonstrando-se assim a importância do equilíbrio entre a razão e a emoção. Segundo as autoras, a inteligência emocional pode ser desenvolvida por meio de vivencias individual e coletiva, mas requer persistência nas ações educacionais que mobilizam a educação e a sociedade para que se desencadeiem os sentimentos de amor, equilíbrio, respeito ao próximo, valorização do ser humano e harmonia nas relações.

Os cinco desejos básicos do ser humano, segundo os ensinamentos do Mestre Massaharu Taniguchi descritos no Modulo de Estudo da Seicho-No-le (2011, p. 160), são: "Ser amado, ser reconhecido, ser útil, ser elogiado e ser livre". Na organização dos ensinamentos da Seicho-No-le há uma associação responsável pela divulgação e preleção da "Educação da Vida", a qual parte do princípio que a reeducação do adulto é a base para a educação da criança e esta se da através de sorrisos, elogios e palavras de incentivo (SNI, 2011). O homem segundo Freire (2001), é responsável pela construção do seu saber e pela busca dos meios que o levam a desenvolver-se e aprimorar-se em suas capacidades, sendo ele o sujeito responsável pela sua educação social. Segundo o autor, o educador tem como função mediar a transmissão de informações necessárias para a construção de identidades, bem como incentivar e estimular para o desenvolvimento das capacidades que corroboram com a qualidade de vida.

Em relação as necessidades educacionais atuais, segundo Santin (2003), cultivar a sensibilidade nas escolas poderá contribuir para criar uma paisagem mais humana, com mais paz e bem-estar. Esses pressupostos vão de encontro aos objetivos das práticas pedagógicas propostas pela Superintendência de Atividades dos Educadores da Seicho-No-le, as quais visam desenvolver o ser humano em harmonia com todos os aspectos da vida (SNI, 2011). A Comissão Internacional sobre a Educação para o século XXI define que a educação deve organizar-se em torno de quatro aprendizagens fundamentais: "aprender a conhecer, aprender a fazer, aprender a viver juntos e aprender a ser" e afirmam que estas serão, ao longo da vida, os pilares para conhecimento (DELORS, 2006).

Supondo auxiliar as disciplinas das ciências humanas, com soluções para os problemas atuais, foram relacionadas as necessidades da educação atual para as questões de Educação Ambiental as práticas propostas pela Superintendência dos Educadores da Seicho-No-le, as quais foram descritas como uma sugestão para os educadores físicos, ressaltando a importância dos aspectos educacionais dessa área do conhecimento em entender o ser humano como um ser uno que se movimenta, brinca e sente (SANTIN, 2003). 


\section{Projeto Educação da Vida - Diário de Elogios: Caminho para o sucesso da aprendizagem}

Identificação e localização do original no Site Seicho-No-le do Brasil (SNI, 2011); Link: Educadores; Menu: Projeto nas escolas/Diário de elogio.

Em conformidade com a velocidade eletrônica, o século XXI requer um sentimento coletivo e neste contexto, a educação deverá possibilitar experiências para aprendizagem, as quais aprimorem a criatividade para construir novos conhecimentos e as habilidades para acessar fontes de informação, estimulando o aluno a aprender fazer melhor aquilo que ele já faz bem (BELLUZZO, 2005 apud FERNANDES e BARBOSA, 2006). Segundo as autoras, esse processo possibilita nortear a educação para as transformações da sociedade e do desenvolvimento humano.

Como possibilidade para realização de um trabalho educacional de qualidade, a Superintendência dos Educadores da Seicho-No-le enfatiza a importância do elogio e analisa os resultados através do Diário de Elogios. Para desenvolver essa prática procede-se do seguinte modo:

No inicio do ano entrega-se aos alunos um caderno contendo o nome completo do aluno e um elogio (mesmo sem conhecê-lo). Pode ser uma frase receptiva, como por exemplo: "Seja bem vindo" ou "Sua presença é importante nessa escola".

Junto ao caderno envia-se um bilhete aos pais, solicitando que coloquem uma foto com aspecto alegre do filho (a) na primeira folha do caderno. Deve-se ainda informar aos pais que este material faz parte do trabalho educativo e que eles participarão do processo elogiando o filho (a) diariamente. O caderno e levado para casa todos os dias e deve voltar pra escola com o elogio dos pais. No inicio da aula os cadernos são recolhidos e a medida que o tempo permite, a professora confere o elogio dos pais e abaixo escreve um elogio para o aluno, enfatizando suas capacidades.

Iniciar a aula com a seguinte oração seguida pelas afirmações positivas. "Agradecemos a Deus pelos nossos pais, pelos nossos irmãos, pelo sol, pelo vento, pela chuva. Temos certeza que o dia de hoje será maravilhoso! Agradecemos a Deus por todas as pessoas que trabalham em nossa escola. Muito obrigado!”. Em seguida, as palavras positivas: “Eu faço! Eu posso! Eu consigo! Tudo consigo fazer porque tenho capacidade infinita! Sou filho de Deus! Muito obrigado!"

No final da aula o caderno é devolvido aos alunos e conforme o tempo permita, pode-se pedir para os alunos que compartilhem seu elogio com os demais. Pode-se também elogiar o familiar que está participando, como forma de incentivo. Quando estiver ocorrendo alguma dificuldade em corrigir algum aspecto do aluno, recomenda-se solicitar nesse caderno uma atividade, como por exemplo, pedir ao aluno que escreva $X$ vezes a frase: "Eu sou bom em matemática e sou a alegria dos meus pais", sem obrigar a realização da mesma. Ao retornar com a tarefa feita, a professora escreve um elogio seguido de Parabéns!

Esta prática tem como público alvo as séries iniciais do ensino básico, mas sendo o elogio um dos cinco desejos do ser humano (MÓDULO DE ESTUDO DA SEICHO-NO-IE, 2011), nada impede de ser realizada em todas as ações educacionais. O tempo estimado para realização desta é de um ano, ou seja, todo o período letivo. Caso algum familiar não cumpra o determinado, o professor deve enviar-Ihe um cartão vermelho (significando advertência), escrito a seguinte frase: "Prezados pai e mãe, eu acredito na capacidade do seu filho (a). Elogiar é acreditar na capacidade, portanto conto com a colaboração de vocês nos elogios diários! Muito Obrigado!".

Ressalta-se que para esse projeto funcionar plenamente, antes de tudo o professor precisa acreditar na capacidade dos seus alunos. É uma atividade simples de ser realizada e com o poder da palavra, segundo relatos de educadores que já aplicaram esse projeto, (SNI do BRASIL, 2011), qualquer pessoa é capaz de manifestar as suas capacidades. 


\section{Diário do relógio de sol}

Recentemente a Seicho-No-le lançou o livro "Diário do Relógio de Sol" de autoria da Professora Junko Taniguchi (2011). Este livro é editado em formato de diário, com páginas personalizadas para anotar todas as boas ações, idéias e fatos positivos ocorridos durante o dia. Não é necessário adquirir o livro, pois esta prática pode ser realizada em um caderno comum.

Desde remotos tempos os homens egípcio e babilônicos ao observar o Sol, perceberam que este provocava a sombra dos objetos. A partir dessa percepção, observarão que ao longo do dia o tamanho destas sombras variavam e através de uma vareta fincada no chão na posição vertical começaram a estimar o tempo. Assim foi criado o primeiro relógio de Sol, conhecido por Gnômon (BRASIL ESCOLA, 2011).

Esse relógio registra apenas as horas em que o sol brilha, fato que se relaciona aos ensinamentos da Seicho-No-le contidos no Módulo de Estudo da Seicho-No-le (2011, p. 14), quando o Mestre Massaharu Taniguchi ensina a registrar na mente somente momentos alegres e positivos do dia: "Acendendo a "Luz" em nossa mente, logo se concretizará a "Luz" em nossa vida".

De fato a vida humana é social e integrada por diferentes relações interpessoais as quais constroem os cenários do cotidiano (ORTEGA et. al., 2002). Nas diversas relações encontram-se a origem dos problemas e as possibilidades de resolvê-los, os quais oportunizam a melhoria das condições de vida. Independente da cultura, todas as pessoas aspiram pela paz e vivem lutando para melhorar a própria qualidade de vida, estendendo estas melhorias aos ambientes. Assim, os autores sugestionam a adoção de uma posição teórica comunitária, retirando das necessidades básicas comuns a melhoria da qualidade de vida e do progresso pessoal em busca do desenvolvimento de uma identidade coletiva, como um recurso do qual a educação se dispõe para ensinar os seres humanos a perceberem-se e a perceber nos demais as potencialidades de transformação e aperfeiçoamento.

Esta prática tem como principal objetivo ressaltar a importância das ações positivas para melhoria da qualidade de vida. Sendo assim, sugestiona-se a aplicação desta no intuito de atender os requisitos de uma educação transformadora, proposta pela Educação Ambiental. Esta pode ser aplicada em toda a comunidade escolar e também na educação não formal. $O$ tempo de aplicação e a troca de informações são livres e além de propor aos seus alunos e as pessoas com as quais convive e realizam trabalhos o professor poderá ter o seu diário pessoal, participando das transformações como um ser humano comum.

\section{Poema em louvor aos pais}

Identificação e localização do original no livro: Educação do filho de Deus (KEIYO, 2007, p. 199).

No mundo existem influencias em constante interação as quais contribuem para o desenvolvimento psicológico do ser humano. Para que se possa pensar e ver os aspectos ecológicos complexos, vivos, dinâmicos e intensos, precisa-se desenvolver as diversas percepções (GOLDBERG, et. al. 2005). Conforme os autores, a pessoa está em constante fase de desenvolvimento e este se dá através de reciprocidades entre elas e com os ambientes nos quais se inserem e transitam.

Em relação a investigação ecológica, Portugal (1992, apud GOLDBERG, et. al. 2005) afirma que as características dos sujeitos e do meio e os processos que ocorrem devem ser vistos como "interdependentes" e analisados em "termos sistêmicos". Assim, segundo o autor, é possível identificar processos de interação entre o sujeito e o mundo em transformação. 
A seguinte prática propõe escrever lembranças emocionantes, capazes de fragilizar e sensibilizar o ser humano. Como toda a autobiografia, essa obra será verídica e única e segundo os ensinamentos da Seicho-No-le é preciso antes de tudo, agradecer aos pais. (TANIGUCHI, 2007). Como todas as criaturas existentes, incondicionalmente o ser humano encontra-se na condição de filho, portanto esta prática pode ser direcionada a todos os setores educacionais. Não há um tempo especifico para a conclusão desta, portanto pode ser predeterminado pelo profissional condutor. O principal objetivo é ressaltar a importância de cultivar as raízes existenciais e promover a harmonia nos ambientes familiares através da produção de alguns versos exprimindo todas as lembranças alegres e emocionantes que se tem da infância com os pais em forma de poesia, procurando expressar nas palavras sentimento que os alegram.

Ao escrevê-la poderá ressurgir algum ressentimento antigo contra os pais. Caso isso ocorra, a Seicho-No-le ensina que se deve perdoar e substituir o ressentimento pelo sentimento de gratidão. A produção é livre, portanto a escrita não necessita ser em conformidade com as normas poéticas e a rima é opcional.

\section{Memorial do professor}

Nos ensinamentos da Seicho-No-le contidos no livro A Verdade da Vida vol. 25 constam as seguintes palavras:

O passo fundamental é explorar o interior de si mesmo. [...] Aquele que não explora o interior de si, só será capaz de contar com uma limitada força superficial. Mas aquele que explora o seu interior em busca de algo, acaba encontrando coisas mais valiosas do que o objeto inicial de sua busca (TANIGUCHI, 2009, p. 19).

O memorial do professor consiste em uma prática de retomada e avaliação da trajetória pessoal no ambiente acadêmico e profissional. Compilado por Gildenir Carolino Santos é proposto pelos estudos em Educação da Vida da Seicho-No-le como construção de uma autobiografia que tem como objetivo desenvolver uma percepção qualitativa do significado da vida e do trabalho como educador. É uma narrativa histórica e reflexiva que ressalta momentos marcantes e significantes na formação profissional e expressa a evolução particular do autor (SANTOS, 2005).

Para elaboração do memorial, Santos (2005) sugere a seguinte estrutura:

\begin{tabular}{|c|c|}
\hline 1 Analisando minha caminhada de formação & $\begin{array}{c}1.1 \text { As incertezas iniciais } \\
\text { Os eventos que construíram o(a) profissional que sou }\end{array}$ \\
\hline $\begin{array}{r}1.3 \text { As ações e reações } \\
\text { 3 As referências iniciais (olhar comparativo do que tive } \\
\text { no inicio com o que tenho hoje) }\end{array}$ & $\begin{array}{c}2.1 \text { As significações implícitas } \\
2.2 \text { Os novos caminhos que se apontam }\end{array}$ \\
& $\begin{array}{c}3.1 \text { Os novos interlocutores } \\
\text { 3.2 Novos olhares e perspectivas de ação }\end{array}$ \\
\hline
\end{tabular}

Quadro 1: Elementos textuais para elaboração de memorial. Fonte: Santos (2005, p. 4). 
De acordo com Fernandes e Barbosa (2006), para que a universidade assuma uma postura transdisciplinar, proposta pela Educação Ambiental, é necessário considerar as percepções individuais. Segundo as autoras, os opostos se complementam na construção de unidades complexas e diferenças nas experiências educacionais tornam possível a construção de projetos coletivos que visem a solução para os problemas na construção do conhecimento.

\section{Conclusões}

Ao abordarem soluções para problemas na educação as áreas das ciências humanas enfatizam aspectos relacionados ao aprimoramento das percepções para o desenvolvimento das capacidades de se relacionar harmoniosamente nos diversos ambientes. As disciplinas dessas ciências propõem aos educadores trabalhar para o desenvolvimento aprimorado da inteligência emocional, visando atingir o necessário equilíbrio entre a emoção e a razão em meio as transformações culturais. Promovendo o autoconhecimento proposto pela Educação Ambiental, ressaltaram-se as ações que possibilitam a sensibilização do educando e das comunidades através de reflexões globais sobre valores, capacidades e comportamentos sociais.

Tendo como principal objetivo, construir bases metodológicas para auxiliar os profissionais de Educação Física a contribuírem significativamente com as questões de Educação Ambiental, resgataram-se aspectos filosóficos da Educação Física que, ao associá-los as necessidades atuais da educação percebeu-se a possibilidade de inovar as relações e ampliar as atuações educacionais dessa disciplina. Surgem assim novas oportunidades de contribuir para as ações experimentais de transformação cultural, proposta pela Educação Ambiental.

As práticas pedagógicas propostas pela filosofia de vida Seicho-No-le visam o desenvolvimento evolutivo global do ser humano e seguindo as recomendações contidas nos ensinamentos do Mestre Massaharu Taniguchi, de não impor a realização destas e sim, ser exemplo de boa conduta, proporcionam o aprimoramento da percepção holística de forma natural. Nessas práticas os educadores poderão encontrar bases metodológicas, as quais relacionadas ás necessidades educacionais podem participar na construção das interfaces da Educação Ambiental. Os ensinamentos da filosofia Seicho-No-le abrangem aspectos da educação formal e não formal e assim propicia a reeducação do próprio educador, que como ator social também sofre com as influencias do pensamento moderno, e dessa forma pode-se deduzir que contribuem para construção de uma ética coletiva.

Assim, como contribuição á Educação Ambiental, disponibiliza-se o presente artigo com sugestões de práticas filosóficas que de forma livre possibilitam o desenvolvimento da inteligência emocional. Através da disciplina de Educação Física encontra-se a oportunidade de trabalhar esses aspectos de forma criativa, proporcionando a transformação do pensamento individual para uma percepção mais holística do mundo, refletindo nos movimentos corporais que compõem as ações cotidianas o desenvolvimento verdadeiramente evolutivo, natural e harmonioso do ser.

\section{Referências Bibliográficas}

AMARAL, J. J. F. Como fazer uma pesquisa bibliográfica. Disponível em: <http://200.17.137.109:8081/xiscanoe/courses1/mentoring/tutoring/Como\%20fazer\%20pesquisa \%20bibliografica.pdf> Consultado em: 27/Ago. 2011. 
ARAÚJO, D. S. M. S, ARAÚJO C. G. S. Aptidão física, saúde e qualidade de vida relacionada à saúde em adultos. Revista Brasileira de Medicina do Esporte, v. 6, n. 5 - Set/Out. 2000.

BRANDOLT, P. R. M. Processo de trabalho e saúde do professor do ensino médio: uma abordagem ergonômica. 201f. Tese Doutorado - Programa de Pós-Graduação em Engenharia de Produção, UFSC, Florianópolis, 2006.

BRASIL ESCOLA. Relógio do sol. Disponível em : <http://www.brasilescola.com/geografia/relogiosol.htm> Acesso em 08/Dez. 2011.

DELORS, J. Educação: um tesouro a descobrir. 10a ed. São Paulo: Cortez. Brasília, DF: MEC/UNESCO, 2006.

FERNANDES, C. A. V., BARBOSA, I. M da S. P. Educação e Mudança. Revista Educação, v. 1, 2006.

FESTIVAIS PAN-HELÉNICOS. Disponível em: <URL:http://www.infopedia.pt/\$̧festivais-panhelenicos> Acesso em: 30/Nov. 2011

FREIRE, P. Pedagogia da autonomia: saberes necessários à prática educativa. 6ạ ed. São Paulo: Paz e Terra, 1997.

GARCIA, R. P.; LEMOS, K. M. A estética como um valor na educação física. Revista paulista de educação física, 17(1), 32-40, 2003.

GIL, A. C. Como elaborar projetos de pesquisa. 4a ed. São Paulo: Atlas, 2002.

GOLDBERG, L. G., YUNES, M. A. M., FREITAS J. V. de. O desenho infantil na ótica da ecologia do desenvolvimento humano. Psicologia em Estudo, Maringá, v. 10, n. 1, p. 97-106, Jan./Abr. 2005.

GRÜN, Mauro. Ética e educação ambiental: a conexão necessária. 6a ed. Campinas, SP: Papirus, 2002.

JACOBI, P. Educação ambiental, cidadania e sustentabilidade. Cadernos de Pesquisa, n. 118, 2003.

KANUMA, K. Educação do Filho de Deus, v. 2. Tradução Seicho-No-le do Brasil, 3ạ ed. São Paulo, 2007.

KANUMA, K. Educação do filho de Deus, v.1. Seicho-No-le do Brasil, São Paulo, 2007.

LEITE, R. A. P., HARTMANN, C. A Temática Ambiental como Proposta Transversal da Educação Física no Ensino Médio. Piracicaba: Universidade Metodista de Piracicaba - UNIMEP, 2007.

MARINHO, A; INÁCIO, L. D. Educação Física, meio ambiente e aventura: um percurso por vias instigantes. Revista Brasileira de Ciências do Esporte, v. 28, n.3. Campinas-SP: Autores Associados, 2007. 
MARINHO, A. Lazer, natureza e aventura: compartilhando emoções e compromissos. Revista Brasileira de Ciências do Esporte, v. 22, n. 2, p.143-153. Campinas (SP): Autores Associados, Jan, 2001.

MORIN, E. Os sete saberes necessários à educação do futuro. São Paulo: Cortez/UNESCO, 2002.

MONTEIRO, S. V. Subjetividade, Amizade e Montanhismo: Potencialidades das experiências de lazer e aventura na natureza. Revista Motrivivência, ano XVI, n‥ 22, p. 71-91. Jun. 2004.

ORTEGA, R., DEL REY R. Estratégias educativas para a prevenção da violência. Brasília: UNESCO, UCB, 2002.

PAPALIA, D. E., OLDS, S. W. Desenvolvimento Humano. 7ạ ed. Porto Alegre: Artmed, 2000.

PLANALTO, LEI 9.795/1999. Dispõe sobre a educação ambiental, institui a Política Nacional de Educação Ambiental e dá outras providências. Disponível em <http://www.planalto.gov.br/ccivil_03/Leis/L9795.htm> Acesso em: 09/Jan. 2012.

REIGOTA, M. O que é Educação Ambiental. São Paulo: Brasiliense, 2001.

RÊGO, C. C. de A. B., ROCHA, N. M. F. Avaliando a educação emocional: subsídios para um repensar da sala de aula. Ensaio: aval. pol. públ. Educ., Rio de Janeiro, v. 17, n. 62, p. 135-152, Jan./Mar. 2009.

SAMPAIO, D. M. A pedagogia do ser: educação dos sentimentos e dos valores humanos.

Petrópolis, RJ: Vozes, 2004.

SANTIN, S. Educação Física: uma abordagem filosófica da corporeidade. 2a ed. Revista ljuí: Unijuí, 2003.

SATO, M., CARVALHO, I. C. M. e cols. Educação Ambiental: pesquisa e desafios. Porto Alegre: Artmed, 2005.

SEICHO-NO-IE DO BRASIL (orgs). Módulo de estudo da Seicho-No-le. Superintendência das atividades dos preletores: Módulo I, 5a ed. 2011.

SEICHO-NO-IE do BRASIL. Disponível em: < http://www.sni.org.br/oque.asp > Acesso em 20/Ago. 2011.

. Organização da Seicho-No-le. Disponível em: 〈http://www.sni.org.br/organizacao.asp> Acesso em: 15/Dez. 2011.

. Meio Ambiente. Disponível em:

<http://www.sni.org.br/meioambiente/quemsomos.html> Acesso em: 15/Dez. 2011.

. Superintendencia dos educadores. Disponível em: <http://www.sni.org.br/educadores > Acesso em: 15/Dez. 2011. 
. Diário de elogio. Disponível em:

<http://www.sni.org.br/educadores/diario de elogios.asp> Acesso em: 15/Dez. 2011.

SANTOS, G. C. Roteiro para elaboração de memorial. Campinas, SP. 2005.

TAHARA, A. K.; FILHO, S. C. Atividades Físicas de Aventura na Natureza (AFAN) e Academia de Ginástica: Motivos de Aderência e Benefícios Advindos da Prática. Revista Movimento, Porto Alegre, v. XV, n. 3, p. 187-208. Jul./Set. 2009.

TAHARA, A. K.; FILHO, S. C.; SCHWARTZ, G. M. Meio Ambiente e Atividades de Aventura: significados de participação. Revista Motriz, Rio Claro, v. 12, n. 1, p. 59-64. Jan./Abr. 2006.

TANIGUCHI, J. Diário do Relógio do Sol. Seicho-No-le do Brasil. São Paulo, 2011.

TANIGUCHI, M. Expressemos Deus em nos mesmos, no nosso modo de viver. Revista Fonte de Luz, n. 400, p. 27. São Paulo: Seicho-No-le do Brasil, 2007.

TANIGUCHI, M. A Verdade da Vida. v.14, 6ạ ed. Tradução Seicho-No-le do Brasil, São Paulo, 2009.

. A Verdade da Vida. v. 25. Tradução Seicho-No-le do Brasil, São Paulo, 2009.

. A Cartilha da Vida. v. 1. Tradução Seicho-No-le do Brasil, São Paulo, 2007. 